\title{
Contract Instructing within Aotearoa New Zealand's Secondary Schools
}

New Zealand Journal of Teachers' Work, Volume 11, Issue 2, 232-248, 2014

\author{
ALAN HASLIP \\ OENZ- Outdoor Education New Zealand \\ JO STRAKER \\ CPIT \\ SARAH ENGLISH \\ OENZ- Outdoor Education New Zealand
}

\begin{abstract}
Over the last 150 years, outdoor education in Aotearoa New Zealand has evolved from teachers taking students out of school on field trips to running expeditions and adventure activities as part of the curriculum. Recent accidents have increased expectations within society for outdoor leaders, including teachers, to be technically skilled and qualified before taking groups outdoors. This has, prompted many schools to employ qualified contract instructors to deliver parts of their programme. Using a grounded theory approach, this research explores the complex relationships that exist between schools, teachers, and contract instructors. A model outlining different types of communication between schools and contractors highlights how many outdoor education outcomes remain undeclared and implicit. Recommendations are presented to help contractors and schools work together to deliver programmes which continue to achieve a broad range of outcomes.
\end{abstract}

\section{ALAN'S STORY}

In 2011, whilst working alongside a teacher on a series of school tramping trips, I realised we had different expectations and outcomes. Initially, I was provided with some paper work detailing the unit standards and required assessments. Over two separate trips I worked with the group to ensure they knew the material and could be fairly assessed. Then, ten minutes from the van, the teacher said 'well now the students should be able to plan and execute the third tramping trip without any input from us, we want them to do everything so we are just there, you know be self-sufficient'. This was new information and certainly not something I had been preparing them for. The differences may be subtle, but helping students become self-sufficient requires a different pedagogy from one that assesses specific skills. Further conversations revealed that the unit standards were a small part of the programmes' aims, and there were much broader philosophical outcomes that far exceeded assessment topics. Some of these holistic outcomes are difficult to achieve at the best of times, but particularly so when the instructor is unaware of them. 
This experience was similar to other secondary school work; the pattern is to receive a phone call a couple of weeks prior to the trip, discuss the type of activity desired, the likely destination, type of assessments, the group, where to meet, the teacher's experience, and the rate of pay. So I began to wonder-what other mismatches had occurred in my career as a contractor?

\section{INTRODUCTION}

Outdoor education in Aotearoa New Zealand has undergone a number of changes since it was informally introduced (Lynch, 1999, 2006), and is now firmly embedded in the health and physical education curriculum (Ministry of Education, 1999, 2007). For many years, outdoor education was delivered by passionate teachers who believed it provided multiple holistic learning opportunities for students. While this potential learning is still recognised (Ministry of Education, 1999) a series of high profile accidents, leading to increased emphasis on skills and safety, changes to the regulatory framework and accepted best practice standards have prompted schools to employ qualified contract instructors to support their programmes.

Outdoor education is not understood consistently as it has many forms depending on the organisation's goals and philosophy. Lynch describes the historical foundation of outdoor education in New Zealand as "the use of school time and educational resources for recreation, subject-related field work, and communal living in natural physical environments for the purpose of social and moral education, nature appreciation and giving balance to the intellectualism of schooling" (1999, p. 165). During the 1970s and 1980s, educational reforms were introduced that more directly promoted skills and values associated with employability, competence based assessment, and industry qualifications (Lynch, 2006; Straker, 2008). The tangible, measurable skills of adventure activities and associated emphasis on safety and risk management began to dominate, which in turn created a greater need for training and qualifications so that schools could meet safety expectations of society in general and more specifically their Boards of Trustees (Jones, 2004/2005). In addition, the recognition of outdoor education as a curriculum subject placed more emphasis on unit-standard and/or achievement standard assessments, some of which furthered a shift toward a more skill based approach to outdoor education.

Contract instructors are commonly used in secondary schools in two main ways. Firstly, when the school has selected activity skills to be delivered and assessed in order to gain credits toward unit or achievement standards; secondly, to deliver camp based activities which enrich school experiences and are often associated with personal and social development, but are not usually assessed. The term outdoor education is also sometimes used synonymously with Education Outside the Classroom (EOTC). Currently in Aotearoa New Zealand,

EOTC is a generic term used to describe curriculum-based learning and teaching that extends the four walls of the classroom. EOTC can range from a museum or marae visit to a sports trip, an outdoor education camp, a field trip to the rocky shore, or a visit to practise another language. EOTC can take place in the school grounds, in the 
local community, or in regions further afield, including overseas. (Ministry of Education, 1999; 2009, p. 6)

While this leads to significant learning opportunities it is not usually pursuit based and thus does not require specialist contract instructors. A range of industry award qualifications are now offered in many outdoor activities. The New Zealand Mountain Safety Council [MSC] was formed in 1965 as a response to the growing number of accidents in Aotearoa New Zealand's bush and mountain environments with the aim "to promote safe practices in landbased recreational, educational, and adventure activities" (New Zealand Mountain Safety Council, 2011, Para 6.). The flow-on effect from this was the creation of the first formal training courses for the outdoor recreation and education sector. Pressure from the Hillary Commission (predecessor of Sport New Zealand) in the mid-1980s led to the creation of the New Zealand Outdoor Instructor's Association [NZOIA] to "provide a nationally recognised assessment scheme for outdoor instructors" (New Zealand Outdoor Instructors Association, 2001, para 1.). While some teachers hold these qualifications, many do not, and while they are not compulsory, they are recommended in the Education Outside the Classroom [EOTC] guidelines (Ministry of Education, 2009). There is now increased pressure on schools to support teachers to acquire the "activityspecific outdoor training and/or qualifications" (Ministry of Education, 2009, p. 36 ), or to use qualified contract instructors to deliver these pursuits, or review the content and delivery of their programmes.

The Adventure Activities Regulations (Department of Labour, 2011, p. 8) make qualifications mandatory to commercial operators when an appropriate qualification exists. While schools and teachers are exempt, any third party providers such as outdoor education centres and instructors contracted by schools are expected to hold these qualifications. While this offers some leeway for teachers who do not hold qualifications, there is still an expectation that employers, governing bodies, teachers, and volunteer instructors, have a responsibility to ensure their practices are consistent with accepted best practice standards.

With the use of contract instructors becoming an integral part of outdoor education in many school communities, it is important that the aims, pedagogy and philosophy of the programmes are not lost in the process of compliance, safety management, and assessments. To date nothing has been published detailing how teachers can maximise the skills, knowledge and experience of contract instructors within secondary school outdoor education programmes. This article helps to fill this gap by investigating the complex relationship between schools, teachers, and contract instructors from the perspective of the contract instructor.

\section{METHODOLOGY}

A constructivist grounded theory approach (Charmaz, 2006) was adopted because of the lack of relevant empirical literature regarding the relationship between contract instructors and schools. Grounded theory is a useful approach when little is known about the topic as it explores information from the ground up. Theories can be constructed using the data gathered from participants even in the absence of supporting literature (Strauss \& Corbin, 
1998). Glaser and Strauss first presented grounded theory as a research methodology in The Discovery of Grounded Theory (1967). They were responding to the inability of traditional research methods to capture the complexities between participants, the topic and the researcher's involvement (1967, p. 631). Charmaz (2006) developed a constructivist approach to grounded theory, which recognises that conceptual categories arise through our interpretations of data rather than emanating directly from the data. A constructivist stance asserts that reality does not lie dormant within objects, but is built up by individuals as they assign meaning to the world around them (Burr, 2003). The processes of constructivist grounded theory still follow traditional procedures of grounded theory by examining the data, making comparisons, developing categories, and building theoretical principles through careful analysis. The constructivist approach however, recognises that this work does not occur in a social vacuum, but is interactive. The researcher is part of the process, challenging the premise that the emergent ideas are factual in their own right. Instead they are considered to be interpretations of the participants and the researcher.

This methodology requires both initial sampling where data is gathered and themes begin to emerge, and theoretical sampling where those themes are then tested and refined before they can become empirical theories (Charmaz, 2006). Limited time and resources meant this research did not move onto the theoretical sampling stage, although it did follow the framework of grounded theory to the point where a values-based model was developed. However this is yet to be tested and refined. The purposive sample, while limited in number, provides a useful base line for understanding the phenomenon of contract instruction in secondary schools in Aotearoa New Zealand.

\section{METHODS}

Guidelines for participant selection stipulated that potential participants must hold at least one NZOIA activity specific industry award, have worked for a minimum of three different secondary schools, and worked as a contract instructor within the last three years. Full-time contractors were hard to locate, so the amount of secondary school work ranged from five weeks to eight months of the year.

A pilot interview was conducted in which the questions were tested and refined prior to interviewing any participants. The interview schedule was also adapted during the interview process to address emerging themes (Strauss \& Corbin, 1998, p. 629). Face to face and phone interviews were completed with two female and three male contract instructors. Data gathered in the interview process was transcribed verbatim and coded line by line as described by Charmaz (2006). Careful attention was paid to the initial coding process to stay close to participant statements and a number of analytical memos were made alongside the initial coding process to highlight emerging themes.

In the following section the coded themes are described and explained using exemplars from the transcripts to support each code, using the language of the participant to both demonstrate transparency of the research process and strengthen the findings. 


\section{FINDINGS}

Keeping in mind that coding in grounded theory "is more than a way of sifting, sorting and synthesizing data, as is the usual purpose of qualitative coding" (Charmaz, 2006, p. 71), the themes have been restructured to develop a model to enhance an understanding of the complex relationship between schools and contract instructors. These themes therefore have been divided into two major areas of communication; logistical components (LCs) and valuesbased programme outcomes (VPOs). A third theme, which addressed the building of relationships between contractors and teachers, was also constructed.

\section{Logistical components}

The three main logistical components included technical expertise and qualifications, contractual agreements, and programme safety planning.

\section{Technical expertise}

The research participants felt they were mainly contracted because of their technical knowledge, qualifications, and skills as they were more likely to be asked about their NZOIA awards and first aid qualifications than their academic qualifications: "I find that you're brought in as a contractor because they [the teachers] don't have the skills themselves to run those things" (Participant 1).

All of the research participants had tertiary level qualifications specific to outdoor education or outdoor instruction. On-going academic and industry training was also undertaken by all participants: one was involved in postgraduate study at the time of research, and another two had recently completed post graduate study. While they had academic backgrounds, this was rarely discussed in initial negotiations.

In addition to providing technical expertise, they were expected to motivate, assess, and enhance learning, though the initial contact rarely asked about those attributes. Participant three who had been an instructor but had recently trained as a teacher noted the wider roles of being an instructor in saying:

The instructor comes with expert knowledge, is driven by that expert knowledge, so they [the teachers] look up to them for that as providing the safety for them... but they still have to control and get the best out of the students.

While recognising they were employed because of their national outdoor qualifications, they felt their other experience and qualifications were not considered with the same scrutiny.

\section{Contractual agreements}

The research participants felt that contractual information was usually well communicated although each school had a unique process of dealing with contract instructors. Once the contractor had run some trips communication improved, but in general it was felt that the initial information provided by the schools was restricted to the rate of pay, type of activity, time and place, the 
type of assessments and the safety management system, rather than information about the holistic outcomes of the programme.

Many participants noted that the main way they acquired new contracts was via word of mouth recommendations so they were aware that the teachers had probably shared information about them and their skills in working with groups. The first contact was usually a phone call to check availability, typically followed by an informal meeting or second phone call. Even in the follow up meetings, the main talk was around qualifications and logistics. The participants noted that there were usually only a few questions asked about their experience other than the qualifications they held. This meant that finding out more about the programme required the initiative of the contractor, as the following comments note.

On the whole I find it can be quite difficult getting information out of schools, it generally involves at some point having to ring them back and having a sit down and asking —what do you want to get out of it? (Participant 1)

It's usually up to me to find it. To get it off them, l'll send them a form, just a basic form; just saying what the numbers are, medical stuff, and then they'll either give a programme or l'll write one up for them.

(Participant 3)

The participants were usually keen to do the work, so were prepared to fit into the programme as best they could, often feeling it was best not to ask too many questions before they were officially employed.

\section{Programme safety planning}

The initial roles usually included, but were not always limited to, ensuring the safety of students and teachers, delivering pursuit experiences, and assessing students against the designed marking schedule. Safety appears to be the main reason for employing contractors and as such, they are put in charge of those elements, but not given much other information.

Outdoor education varies across schools and age groups, yet the contractors felt that these differences were often not included in discussions around programme plans. It appeared at times, that outdoor education was assumed to be a subject that everyone agreed on and delivered in a consistent way. However, as participant 2 points out, programmes are constantly changing: "Because of the environment you know, the political social environment that we live in; outdoor education is changing".

Some participants felt that some schools understood the significance of these changes whilst other schools were still doing what they have always done.

It's kind of like we're heading out to this destination and we're going to experience rock climbing, kayaking, and tramping. Even though the climbing is terrible here that's what you do on a camp. (Participant 1) 
This sometimes meant contract instructors believed they had a broader grasp of educational outcomes than the teachers as they worked across a variety of programmes, but they felt that often this was unrecognised as they were employed predominantly for safety reasons.

Despite looking after safety, the participants felt that contractors still tended to put their own slant on the sessions they ran, especially when no clear outcomes were provided by the teacher.

Because if I don't know what they [the students] are meant to get out of it I try to make sure I give them what they need; I'll make it up for myself because they [the teachers] haven't given any criteria to follow. (Participant 1)

The research participants noted that schools focussed mainly on safety and did not usually ask contract instructors about their personal values and philosophy. Contractors felt that the relationship with schools centred on their qualifications, not on who they were and what they could offer the students.

\section{Values-based communication}

Much of the values and philosophical communication remained unspoken and it was only after a number of trips that the contractors became aware of it. As participant 1 noted, these extra outcomes were just implied rather than given specifically'. These outcomes however are nuanced and certainly not uniform across all programmes. They are linked to the school's ethos, and the teacher's philosophy and values.

\section{School ethos}

Working with a range of schools highlighted the different approaches and values that underpinned different schools' charters. What drives a school and makes it unique is a combination of traditions, values, goals, culture of the staff, and the Board of Trustees. Participant 3 described this as the school's ethos, while other participants referred to it as the philosophy of the school. This underpinning ethos, while crucial, is often not communicated with contract instructors, with participant 5 suggesting, "You can get a sense but I don't think you fully know what's driving the school".

It does however have an influence on many components of the outdoor education programmes including the emphasis on assessment. Participant 5 describes this clearly:

....it's dependent on the...philosophy of the school. You know l've done some programmes where I stand in one place for the day and that's fine, and three bus loads will come up, staggered through the day and they do one climb, I put a tick next to their name and then they walk away, and that's it. Then there are other programmes that say, well we are going to do this assessment but the main focus is that they have a really enjoyable positive rock climbing experience. So I guess it depends on the philosophy, if the assessment drives the programme or if the sort of activity drives the assessment. 
This also demonstrates how the school's ethos directly affects the contract instructor and in some cases dictating the way in which they carry out the activity.

Certainly when I was [contract instructing] you know, you sit there and talk to the teacher on the phone all day blarblarblar; you can get a sense, but I don't think you fully know what's driving the school. Like you know are they bringing their 7th form students out for a leadership day, or are they? Or is there another agenda there; and often the teacher won't necessarily tell you, or you don't necessarily know. (Participant 2)

The ethos can be so deeply embedded that it is just seen as normal and not worthy of mentioning.

Teacher philosophy

Another overriding influence comes from the teacher in charge because they direct and steer the programme, as participant 5 stated.

It's the teacher that's running the programme, probably the head of department, who kind of steers the programme in the direction of their philosophy, you know there's lots of flexibility in outdoor education and the programme that you want to choose, and yea, and everyone has a completely different idea of what outdoor education is or what it should be.

Each teacher has developed a set of practices that works for them and that sets the tone of the experience. These subtle practices often set the tone of an activity or trip and require the contract instructors to pick up on these implied values.

Yea, you sort of pick it up, depending on how many coffee stops ... But if you don't stop for coffee the whole time; then you know, it's just getting from point $A$ to point $B$ and you realise that, oh ok if they haven't stopped then they are pretty serious about this programme. (Participant 3)

\section{Values}

Besides the teachers who have distinct values, each participant also articulated diverse personal philosophies. Some of the participants held a strong environmental focus, while others emphasised personal development, team building, and creating enjoyable experiences. However, the participants often remained silent about these as they tried to fit in with the teachers and the school because they wanted more work. However as participant 1 noted:

You kind of know what they're trying to do and then you can also start to put your own influences in on it a little bit because l'm sure everybody does. I mean at the end of the day we all teach to our own beliefs and values and so you want to know what they're specifically after, then you start twisting and moulding it, shaping it to your slant. 
While there were often assessments and expected outcomes many parts of the programme were driven by the teachers' individual beliefs and values, which remained implicit in a range of practices, but rarely spoken of explicitly.

\section{Relationships}

Three elements of the relationship between contract instructors and teachers, which were raised by the participants, included tacit knowing, dissatisfaction, and conflict.

\section{Tacit knowing}

A tacit working relationship between contract instructors and schools usually developed over a period of time when the relationship was on-going. This relationship goes through a stage of trial and error over the first two or three trips, but gradually the contract instructor picks up the subtle inferences which reveal the ethos of the school, as well as the teacher's values and philosophy. Participants used phrases like; "I know what the go is", but these messages remained implicit rather than being openly discussed and debated.

I know what the camps are, I know what the outcomes of all their camps are because I've done them for so many years it's like I know what he's [the teacher] trying to get out of it, and well we are kind of at that point where we don't need to talk so much, because we have been through that process. (Participant 1)

These tacit working relationships build up over time as described by participant 1 , however as they are not openly discussed there is no guarantee the contractor fully understands or supports the school's overall philosophy.

\section{Dissatisfaction}

Several participants were moving on from contracting as they felt their input was not always valued. As participant 1 noted, "there is only so long that you can work to someone else's outcomes when it's completely against what you believe". The lack of recognition of skills beyond their technical qualification was also a frustration as they felt they had much to offer philosophically, but were often used as the safety person or expected to run the abseil activity without even getting to know the students or contribute to the overall programme.

\section{Conflict between teachers and contractors}

The principal area of conflict between the teacher in charge and contract instructor was around a difference in philosophy or as participant 1 noted, a value misalignment. Participant 3 described the following scenario:

It was pouring down with rain; the outdoor ed[ucation] teacher wanted me to go and use this rock crag, their philosophy was; the students should still climb in the rain; I saw it as a safety issue, I didn't really want students climbing in the rain so I chose the indoor option and as a result, he said he'll come run the session for me then, and I said yea fine cos I'm not prepared to go out. 
The philosophies are different, but they remain unspoken and often it is only when a conflict arises that they become obvious, though often at the stage when they are difficult to address. Participant 3 also felt that when both the teacher and the instructor hold the same level of activity specific qualification such as NZOIA Rock 1, as in the example above, the chance of conflict increases. While value misalignment and philosophical ideals do not always end in conflict, it was evident that major misalignments created challenging working environments.

\section{DISCUSSION}

The two main areas of communication between contractors and teachers relate to practical logistics and values. The teachers and contractors seem conversant in, and capable of sharing information relating to, logistics, but values often remained unspoken until a conflict arose. To further explore the relationships between teachers and contract instructors a two-part model is presented. Part one relates to communication and part two relates to programme outcomes.

\section{Values Based Programme Outcomes Theory: Part One- Communication}

Secondary school outdoor education programmes are influenced by socio-political trends, current practices, and the personal philosophies of schools and teachers. The use of certain pursuit activities within outdoor education is common practice within schools, and social expectations suggest there is a need for activity specific qualifications. Qualifications of this nature are costly and this has increased the use of contract instructors in some schools.

Many contract instructors hold outdoor education or instructional qualifications from tertiary organisations and outdoor qualification providers (e.g. NZOIA, NZMSC, NZMGA, Skills Active), and thus they have technical and risk management skills to deliver activities commonly used in outdoor education programmes. Many have also developed strong facilitation skills and are capable of adjusting their style of instructing to meet the multiple outcomes. However, when contract instructors are asked to run an activity or trip and not told otherwise, they will, by default, teach what they feel aligns best with their values, beliefs, and philosophy. These may not, however, always align with the school.

In this study values were rarely spoken about or actively communicated by the school, teacher, or the contract instructors. They lay just under the surface of every session. Over time, the participant contactors may have picked up on the subtleties of what the school expected, but even then they were not explicitly discussed. For example, a teacher may proceed in deteriorating weather or turn back depending on their values. Other scenarios that reveal values include how groups are structured, how leadership roles are decided, how the assessments are run, and the style of communication between staff and between staff and students. The contract instructors in this study believed they built up an understanding of the schools' ethos, teachers' philosophy and unspoken outcomes through observing differing approaches to these scenarios, but without discussion, they remained assumptions. 
These assumptions were usually only challenged when an incident or conflict arose, but by then, this was too late to discuss them, as a trusting and respectful relationship had broken down. Dissatisfaction on the behalf of either party would usually result in a termination of the relationship rather than attempt to work through these issues by discussing the contradictions in the values and curriculum outcomes that had caused the conflict in the first place.

When the focus of communication remains at the logistical level then programme outcomes are limited, both parties experience dissatisfaction, and conflict can occur if philosophies remain unaligned.

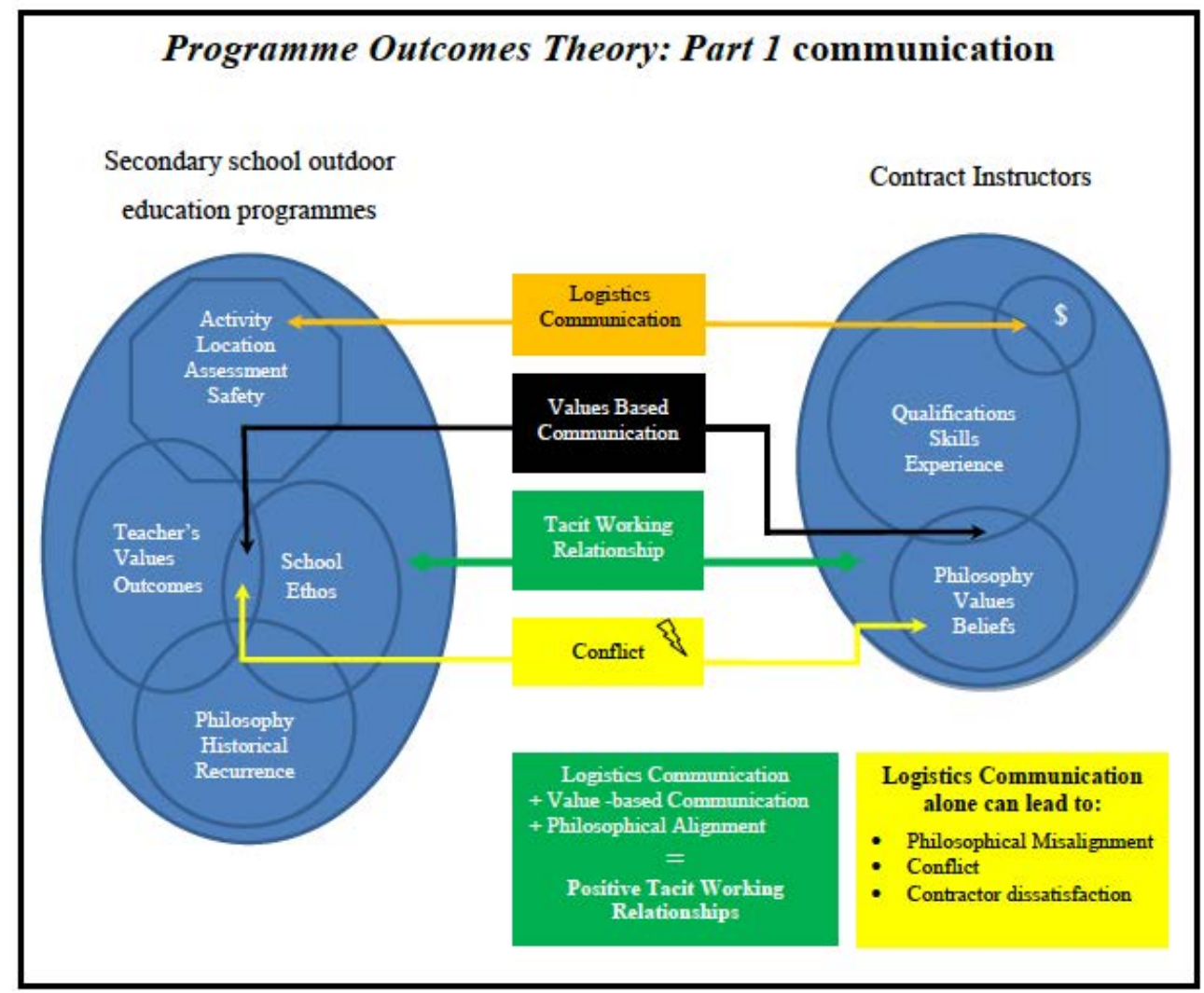

Fig. 1 Programme Outcomes Theory: Part 1

\section{Values-Based Programme Outcomes Theory: Part Two - Outcomes}

Values-based programme delivery is achieved when the contract instructor and school have established sound logistical and explicit valuesbased communication. The contract instructor understands the school's ethos; the teachers' desired outcomes, as well as being able to articulate their own philosophy and values. With this understanding contract instructors can adapt their teaching styles so that the programme delivered to the students is in line with the school's prescribed and desired outcomes. Values-based programme delivery differs from basic programme delivery, because contract instructors are no longer teaching in a way that is solely in line with their own values, and beliefs. This could be achieved by the teacher and instructor having a pedagogical conversation to work out how to collaborate to tailor the programme to best meet the needs of the students in order to achieve 
education and safety objectives. In addition, teachers should communicate their values and the school ethos as articulated in the school's charter. This can help all parties become aware of the learning potential of outdoor education and plan to achieve stated curriculum outcomes through the medium of adventure activity.

The scope of outdoor education in Aotearoa New Zealand secondary schools is vast and most schools design programmes that address a wide variety of outcomes. It is crucial when contract instructors are brought in to help deliver these programmes that the desired curriculum outcomes are not lost. Articulation of key values is important if the programme is to address the more nuanced outcomes that many outdoor education programmes seek to achieve, for example, the key competencies in the New Zealand Curriculum. Furthermore, clear communication can also help to avoid conflict, as well as achieve the stated learning outcomes and curricular expectations more efficiently, as teachers can draw on the strengths and experiences of the contractors beyond their technical expertise.

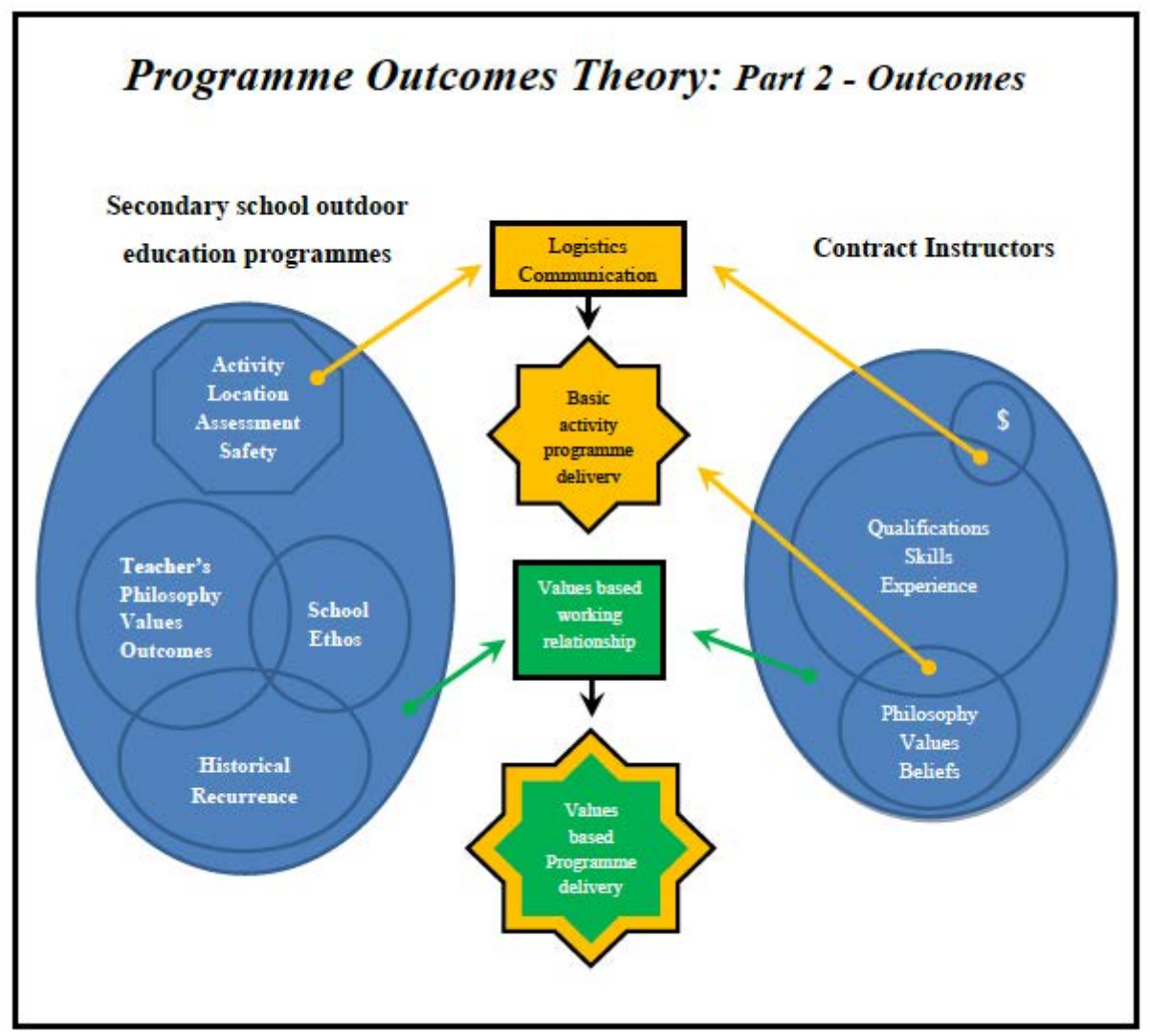

Fig. 2 Programme Outcomes Theory: Part 2

\section{RECOMMENDATIONS}

Establishing working relationships with contract instructors is an important aspect of developing safe school programmes. To fully utilise the skills and expertise of contractors to achieve broader values based outcomes requires a level of communication that moves beyond logistics, technical 
expertise, and assessments. This can be difficult as much communication remains at a superficial level.

Three ways to enhance values based communication include:

\section{Programme documentation}

Contractors receiving documentation relating to the school's ethos, mission statements as well as copies of the overall programme aims before they commence work;

Clearly written philosophical statements.

Outdoor education programmes determining the values they hold, the outcomes they wish to achieve, and the processes they use to support those outcomes and clearly articulating these to contractors. Having these in writing may help contractors understand the subtle programme goals and what is expected of them;

\section{Scenario examples}

Teachers could consider potential areas of conflict, such as assessment, wet weather options, and unacceptable student behaviours, and then discuss these with contractors. This will engage both parties in deeper values discussions and potentially avoid conflict at a later stage.

If none of these recommendations are forthcoming then the contractor themselves should ask questions relating to the underpinning values of the programme and how their work fits in to this bigger picture. A good start would be to ask for the school's charter; the curriculum outcomes for the outdoor education programme; and the learning intentions for the specific activity they are being contracted to assist with.

\section{FUTHER RESEARCH}

Contract instruction within school outdoor education programmes requires further research to increase understanding of this phenomenon in Aotearoa New Zealand. This research is limited to the experiences of five contract instructors who reside in the South Island of New Zealand. Further research is thus required from the perspective of outdoor education teachers who employ contractors to deliver specific aspects of their programmes.

To date the values-based programme model remains un-tested, hence any further research in the area of contractor/teacher relationships will help refine and develop the model.

\section{CONCLUSION}

Outdoor education in Aotearoa New Zealand is moving toward a more regulated climate. This requires some teachers to gain skills and qualifications and/or use qualified contractors to help deliver their programmes. The use of contract instructors creates complex relationships between the school, teacher, contract instructor and the students.

Schools and contract instructors in this study were found to communicate on two levels. Logistics and key contractual expectations are well 
communicated, but there remains a gap when it comes to discussing the values, curriculum outcomes, and philosophies underpinning the programme. These values need to be more explicitly shared both to help contractors fulfil the expectations of the school and to further enhance the potential of outdoor education beyond the technical delivery of recreational adventure activities.

There are considerable opportunities for better collaboration between teachers and contract instructors. This includes sharing expertise, as some teachers lack the confidence to take groups outdoors, whilst contractors usually have less curricular knowledge. Improved communication, especially when speaking of values and the curriculum outcomes sought, could help both teachers and contract instructors reach the personal, social, and environmental outcomes they strive for.

\section{ACKNOWLEDGMENTS}

We would like to thank the two reviewers for their comments on the original submission. 


\section{REFERENCES}

Burr, V. (2003). Social constructionism (2nd ed.). London, United Kingdom: Psychology Press.

Charmaz, K. (2006). Constructing grounded theory: A practical guide through qualitative analysis. London, United Kingdom: Sage Publications.

Department of Labour. (2011). Health and Safety in Employment (adventure activities) Regulations 2011. Retrieved September 20, 2011, from http://www.dol.govt.nz/consultation/adventure-tourism/regulations/hseadventure-activities-regulations-consultation-draft.pdf.

Glaser, B. G., \& Strauss, A. L. (1967). Discovery of grounded theory: Strategies for qualitative research. Chicago, IL: Aldine.

Jones, M. (2004/2005). Is there a disconnection between outdoor education practices and outdoor education principles? Out and About, 13, (29-32).

Lynch, P. (1999). Enterprise, self help and cooperation: A history of outdoor education in New Zealand schools to 1989. Doctor of philosophy, University of Canterbury, Canterbury, New Zealand.

Lynch, P. (2006). Camping in the curriculum: A history of outdoor education in New Zealand schools. Canterbury, New Zealand: PML Publications.

Ministry of Education. (1999). Health and physical education in the New Zealand curriculum. Wellington, New Zealand: Learning Media.

Ministry of Education. (2007). The New Zealand Curriculum. Wellington, New Zealand: Learning Media Ltd.

Ministry of Education. (2009). EOTC guidelines: Bringing the curriculum alive. Retrieved May 26, 2010, from http://eotc.tki.org.nz/EOTC-home/EOTCGuidelines

New Zealand Mountain Safety Council. (2011). "About us". Retrieved 25th August, 2011, from http://www.mountainsafety.org.nz/AboutUs/default.asp

New Zealand Outdoor Instructors Association. (2001). "About us". Retrieved 25th August, 2011, from http://www.nzoia.org.nz/about_us/index.asp

Straker, J. (2008). Unearthing 'the outdoors' in outdoor education. New Zealand Journal of Outdoor Education: Ko Tane Mahuta Pupuke, 2(4), 103-124.

Strauss, A., \& Corbin, J. (1998). Basics of qualitative research: Techniques and procedures for developing grounded theory (2 ed.). Thousand Oaks, CA: Sage. 


\section{ABOUT THE AUTHORS}

ALAN HASLIP

OENZ- Outdoor Education New Zealand

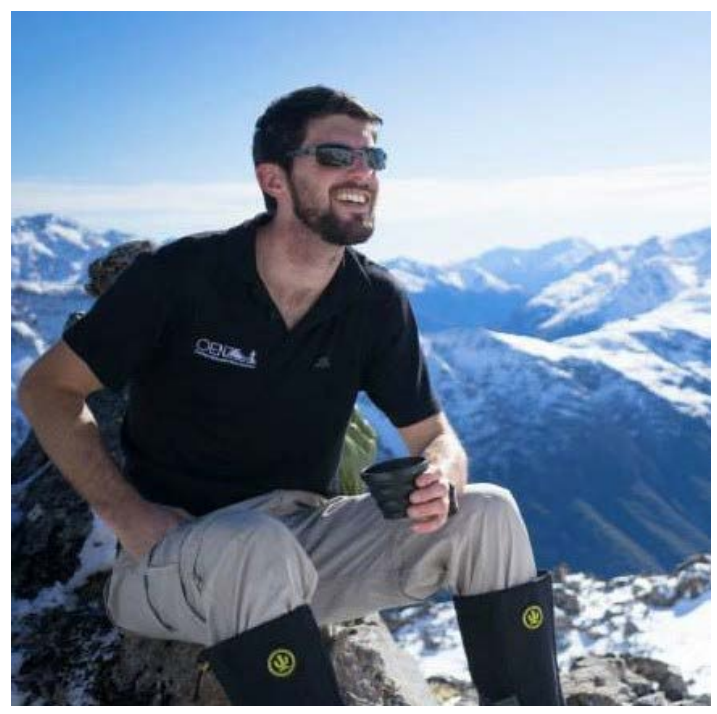

Alan is a managing director of OENZOutdoor Education New Zealand, a passionate outdoors professional, climber and mountaineer. $\mathrm{He}$ is currently developing and running outdoor education programmes in New Zealand and abroad.

Email: alan@oenz.co.nz

JO STRAKER

CPIT - Christchurch Polytechnic Institute of Technology

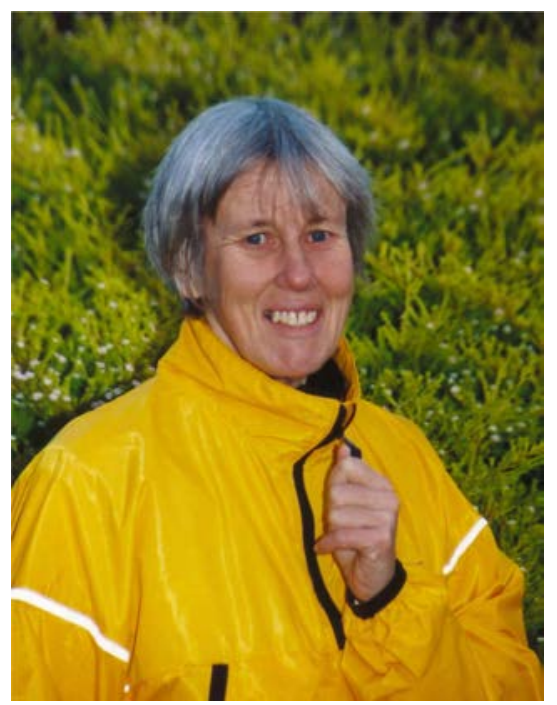

Jo is a senior lecturer on the Bachelor of Sustainability and Outdoor Education at CPIT. She has worked as an outdoor educator in Great Britain, Australia, Canada, Antarctica, and New Zealand. Her research and teaching interests are based around using the outdoors as a medium for positive educational experiences.

Email: Straker.j@cpit.ac.nz 
SARAH ENGLISH

OENZ- Outdoor Education New Zealand

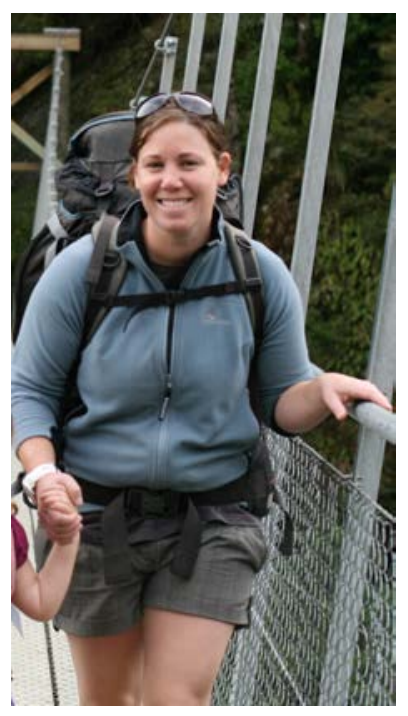

Sarah is a managing director at OENZ- Outdoor Education New Zealand, she is also an expedition leader in the developing world, a keen tramper, climber and mountaineer. Sarah's interests are within the social and behavioural aspects of outdoor education.

Email: sarah@oenz.co.nz 